\title{
Review on the Effect of Heat Stress on Poultry Production and Productivities
}

\section{Getachew Bekele*}

Department of Animal Production and Technology, College of Agriculture and Natural Resource, Gambella University, Gambella, Ethiopia

*Corresponding author: Getachew Bekele, Department of Animal Production and Technology, College of Agriculture and Natural Resource, Gambella University, Gambella, Ethiopia, Tel: +251911550351/+251915607211; Email: gechobek@gmail.com

\section{Research Article}

Volume 6 Issue 2

Received Date: February 01, 2021

Published Date: March 01, 2021

DOI: $10.23880 /$ fsnt-16000260

\section{Abstract}

Heat stress is a situation where too much heat is absorbed by a person, a plant or an animal and causes stress, illness or even death. Therefore, the objective of this review was to compile current knowledge and evidence from literature about the effects of heat stress in poultry production, and productivities. Heat stress is manifested by elevated body temperature, hot, dry skin, lack of sweating and neurological symptoms such as paralysis, headache, vertigo and unconsciousness. Poultry seems to be particularly sensitive to temperature-associated environmental challenges, especially heat stress. In the first days of their life poultry need hot climate $\left(32-38^{\circ} \mathrm{C}\right)$, but the optimal temperature decreases rapidly with age by $2.5-3.0^{\circ} \mathrm{C}$ per week. Birds may use sand baths to dissipate the heat from the body, move to a shaded area or seek a micro-environment that avoids extremely high environmental temperature. Birds rose in an open-sided house at $37^{\circ} \mathrm{C}$ and humidity level of $50-60 \%$ showed signs of panting and wing lifting, elevation of body temperature, lower feed consumption, a higher feed conversion ratio, and lowered body weight gain. In females, heat stress can disrupt the normal status of reproductive hormones at the hypothalamus and ovary leading to reduced systemic levels and functions. Also in males, semen volume, sperm concentration, number of live sperm cells and motility decrease when subjected to heat stress. In egg production, heat stress has a significant harmful impact on body weight, and feed consumption of laying hens at peak production, egg weight, shell weight, shell thickness, and gravity. Both meat type and egg laying chickens respond negatively to high ambient temperatures. Heat stress reduces the relative weights of lymphoid organs like spleen, thymus and cloacae bursa.

Keywords: Chickens; Climate; Environment; Heat Stress

\section{Introduction}

Heat stress is a situation where too much heat is absorbed by a person, a plant or an animal and causes stress, illness or even death. Heat stress is manifested by elevated body temperature, hot, dry skin, lack of sweating and neurological symptoms such as paralysis, headache, vertigo and unconsciousness. It can also cause heat cramps, heat exhaustion and heat stroke which may lead to death. Chicken is the cheapest source of protein available for human consumption, but it cannot tolerate a wide range of climatic variations which affects the production and reproduction.

Temperature, rainfall, solar radiation, atmospheric pressure, etc., were related with fertility. The most potent environmental measures that affect fertility might 
Food Science \& Nutrition Technology

vary depending on geographical locations. The levels of performance of poultry, does not depend only on inherited capacity but, also to a great extent upon the environment [1]. Poultry production and reproduction are affected by various factors such as, feeding, management, disease control, stock density, housing, climate, sire effect, hatch effect, etc.

However, climate change is emerging as a great challenge for poultry industries to sustain the level of production. The worst effects of such climate change are experienced in tropical countries where, a common practice is to house the birds in the open side sheds. Climate variation is one of the major threats to poultry production. Birds of different breeds/strains and of different age, sex, stage of production, and reproduction respond differently to climatic variations. It is highly desirable that data on such effects in different flocks should be generated and analyzed to develop strategies to deal with adverse effects of climate change.

Stress, a response to adverse stimuli, is difficult to define and understand because of its nebulous perception. According to Selye [2]. "Stress is the nonspecific response of the body to any demand", whereas stressor can be defined as "an agent that produces stress at any time". Therefore, stress represents the reaction of the animal organism (i.e., a biological response) to stimuli that disturb its normal physiological equilibrium or homeostasis. Heat stress results from a negative balance between the net amount of energy flowing from the animal's body to its surrounding environment and the amount of heat energy produced by the animal. Environmental stressors, such as heat stress, are particularly detrimental to animal agriculture. The issue of environmental stress has quickly become a great point of interest in animal agriculture, particularly due to public awareness and concerns. Layers in hot climates are exposed to high temperatures, which may lead to a loss of productivity.

High ambient temperatures can be devastating to commercial broilers and layers. Coupled with high humidity, high temperatures can have even more harmful effects. Heat stress interferes with the birds comfort and suppresses productive efficiency. During periods of heat stress the hens have to make major thermo-regulatory adaptations to prevent death from heat exhaustion. As a result, the full genetic potential of the layer is often not achieved. Poultry seems to be particularly sensitive to temperature-associated environmental challenges, especially heat stress. It has been suggested that modern poultry genotypes produce more body heat, due to their greater metabolic activity [3,4]. Understanding and controlling environmental conditions is crucial to successful poultry production and welfare. Therefore, the objective of this review was to compile current knowledge and evidence from literature about the effects of heat stress in poultry production, and productivities focusing on broilers and laying hens.

\section{Effects of Heat Stress on Behavioral and Physiological of Chicke}

Effects of Heat Stress on Behavioral of Chickens: Under high temperature conditions, birds alter their behavior homeostasis seeking thermoregulation, thereby decreasing body temperature. In general, different types of chickens react similarly to heat stress, expressing some individual variation in intensity and duration of their responses. A recent study Mack LA, et al. [5] showed that chickens subjected to heat stress conditions spend less time feeding, more time drinking and panting, as well as more time with their wings elevated, less time moving or walking, and more time resting. The behavior of chickens can significantly influence their growth rate, consequently influencing production costs. Young chicks present high metabolism rates. While their growth rate is fast, their ability to adapt to the changes in environment conditions is poor. Moreover, since they do not present sweat glands in the skin, chickens are highly sensitive and vulnerable to heat stress, particularly when they are young.

Heat stress has negative effects on poultry performance. For instance, Gao reported that, when external house temperature was high, broiler feed intake, feed conversion ratio, and growth rate were reduced. In heat-stressed layers, reduced food intake led to a decrease in egg production and reduced egg weight and quality. Heat stress can also cause changes in intestinal morphology and intestinal flora disorders. Moreover, the immune system of heat-stressed chickens may be affected. An earlier study reported that, under heat stress, chickens displayed a number of clinical symptoms, including open mouth breathing, asthma stretches, rude respiration, stretched and shrunk chest and abdomen, staggered legs, stretched body, restlessness, and weakness. Chickens have an additional mechanism to promote heat exchange between their body and the environment, which are the air sacs. Air sacs are very useful during panting, as they promote air circulation on surfaces contributing to increase gas exchanges with the air, and consequently, the evaporative loss of heat [6].

However, it is worth noting that increased panting under heat stress conditions leads to increased carbon dioxide levels and higher blood pH (i.e., alkalosis), which in turn hampers blood bicarbonate availability for egg shell mineralization and induces increased organic acid availability, also decreasing free calcium levels in the blood. This process is very important in breeders and laying hens, as it affects egg shell quality [7]. The severely affected chickens also presented prostration, convulsions, and even death due to heat exhaustion [8]. Other studies found that under heat 


\section{Food Science \& Nutrition Technology}

stress, chickens showed thermally induced, discontinued (interrupted) asthma, and dropping of both wings, which persisted after the heat stress period. Increased watersticking feathers are a major behavioral response of chickens to resist the stimuli of high temperature [9]. These results imply that heat stress significantly affects the daily behavior of poultry and that investigating the effects of heat stress on the behaviors of the growing and developing baby chicks is of high significance.

Thus, observing the effects of heat stress on different behaviors of the young chicks may reveal the characteristics and regular patterns of their response to acute heat stress (AHS) and to previous heat stress (PHS) of chicks. Heat stress can profoundly affect the productivity of a flock. At environmental temperatures above $33^{\circ} \mathrm{C}$, high mortality and large production losses are readily evident, but at less extreme temperatures, heat stress is often overlooked as a cause for poor growth or subtle losses in egg production and shell quality. In nature, when chickens are exposed to HT, they may use water to splash their combs and wattles in order to increase evaporative cooling from these surfaces [10].

They can also express their normal behaviour such as foraging, thereby ingesting those ingredients that avoid excessive heat loads while being ingested and metabolized. On the other hand, heat-stressed chickens tend to distance themselves from each other, pant, and often stand with their wings drooped and lifted slightly from the body to maximize heat loss [11]. Chickens can increase the flux of heat from the tissues to the environment by behavioural changes. Under HT conditions, the chickens will apply physiological, anatomical and behavioural mechanisms aimed at facilitating heat loss to, or minimizing heat gain from the environment [11]. Excess body heat is removed by four different mechanisms. Convection: Body heat lost to cooler surrounding air. Birds will increase exposed surface area by drooping and spreading wings. Convection is aided with air movement by creating a wind chill effect. Vasodilation-Blood-swollen wattles and comb bring internal body heat to the surface to be lost to the cooler surrounding air. Radiation: Electromagnetic waves transfer heat through the air to a distant object. Body heat is radiated to cooler objects in the house (i.e. walls, ceiling, and equipment). Evaporative Cooling: Rapid, shallow, open-mouth breathing increases heat loss by increasing the evaporation of water from the mouth and respiratory tract. Evaporative cooling is aided by lower air humidity. Conduction: Body heat loss to cooler objects indirect contact with the bird (i.e. litter, slats, cage wire). Chickens will seek cooler places in the house. Chickens will lie on floor and dig into litter to find a cooler place. Radiation, convection and conduction together are called sensible heat loss. The thermoneutral zone of the chicken is generally between 18$25^{\circ} \mathrm{C}$. Within this temperature range, sensible heat loss is adequate to maintain the chicken's normal body temperature of $41^{\circ} \mathrm{C}$.

Above the thermo neutral zone, the efficiency of sensible heat loss mechanisms diminishes. At this point, the evaporation of water from the respiratory tract becomes the major heat loss mechanism of the bird. The evaporation of one gram of water dissipates 540 calories of body heat. At temperatures above the thermo neutral zone, the chicken has to expend energy to maintain normal body temperature and metabolic activities. This diverts energy away from growth and egg production, resulting in performance loss.

\section{Effects of Heat Stress on Physiology of Chickens}

Under high temperature conditions, chickens alter their physiological homeostasis seeking thermoregulation, thereby decreasing body temperature. Heat stress can affect the reproductive function of poultry in different ways. In females, heat stress can disrupt the normal status of reproductive hormones at the hypothalamus, and at the ovary, leading to reduced systemic levels and functions $[12,13]$. Also, negative effects caused by heat stress in males have been shown in different studies. Semen volume, sperm concentration, number of live sperm cells and motility decreased when males were subjected to heat stress [14].

\section{Effects of Heat Stress in Genomics of Chickens}

As climate changes, the weather affecting the major centers of chicken production is expected to become warmer. Elevated temperatures and the increased incidence of heat waves will cause stress in poultry, resulting in reduced productivity, anorexia, heat stress and mortality. Breeding of birds that are genetically more resistant to heat stress will lessen these effects. Both meat type and egg laying chickens respond negatively to high ambient temperatures. Genetic factors clearly influence the bird's physiological response to heat. In layer-type chickens, divergent selection for tolerance to heat produced two lines that differed in survival time in heat. Also, different lines of chickens exhibit different, heritable responses to heat stress.

\section{Effects of Heat Stress on the Immune Response}

Many studies have been conducted to elucidate how stress affects the immune response in animals. Modulation of the immune response by the central nervous system (CNS) is mediated by a complex network that operates bidirectionally between the nervous, endocrine and immune systems. The hypothalamic-pituitary-adrenal (HPA) and the sympathetic-adrenal medullar (SAM) axes constitute the main pathways through which the immune response can be altered [15]. In poultry, several studies have investigated 


\section{Food Science \& Nutrition Technology}

the effects of heat stress on the immune response in recent years. In general, all studies show an immunosuppressant effect of heat stress on broilers and laying hens, although using different measurements. Heat stress suppresses immune function by inhibiting total white blood cell counts and antibody level; thereby increasing mortality in laying hens [16]. Plasma calcium and phosphorous concentrations were reduced by heat stress in 53 to 61 week old laying hens.

For instance, lower relative weights of thymus and spleen has been found in laying hens subjected to heat stress [17] reduced lymphoid organ weights have also been reported in broilers under heat stress conditions [18]. Additionally, Felver-Gant observed reduced liver weights in laying hens subjected to chronic heat stress conditions. Bartlett \& Smith [19] observed that broilers subjected to heat stress had lower levels of total circulating antibodies.

\section{Effect of Heat Stress on Innate Immunity and Biochemical Parameters of Chickens}

Heat stress modulates various behavioural and physiological parameters in poultry species which have been discussed in detail by various reviewers. Various authors recorded variable results indicating that heat stress as either an immune suppressing or immune enhancing factor in chicken's production. Stress affects both innate and adaptive immune response in animals. Heat stress reduces the relative weights of lymphoid organs like spleen, thymus and cloacal bursa. The mechanical barriers, namely mucosa and skin, act as the first line of defense in innate immune response. High ambient temperature is of great concern in all types of chickens operations. Heat loss in chickens is limited due to feathering and the absence of sweat glands. When the temperature and relative humidity exceed the comfort level of chickens, it loses the ability to efficiently dissipate heat.

Heat stress is well known to reduce the reproductive performance of laying hens by interrupting egg production, an effect caused by a reduction in feed intake. Hens exhibit a variety of panting patterns to lose heat as water vapor. The increase in respiration rate leads to a reduction in blood partial pressure of $\mathrm{CO}_{2}$, and an increase in blood $\mathrm{pH}$, resulting in respiratory alkalosis.

\section{Effect of High Temperature on Heat Production and Loss in Feed Intake of Chickens}

Developments in the genetic selection of meat-type birds has led to rapid growth and a high metabolic rate, which is accompanied by a higher heat production level due to increased feed intake. Chickens are homoeothermic and able to maintain body temperature within a narrow range. When the ambient temperature is high the chickens has less ability to dissipate heat [20]. The body temperature of domestic chickens is within a narrow range that is reflected by an upper and lower limit of a circadian rhythm in deep body temperature [11]. When exposed to a hot environment or by performing vigorous physical activity or both, body temperature can rise. This occurs when heat cannot be dissipated within a short time. Conversely, when chickens are exposed to a cold environment, heat is lost from the body and, unless the heat is compensated by extra metabolism, body temperature will decline until the chickens are unable to survive and die.

These effects comprise the concept of the thermo-neutral zone (TNZ), with lower and upper critical temperatures [21]. There is a large variation in the ideal temperature range for different classes and age groups of poultry. This is due to variation in type of birds and in aspects of the environment. As for the optimum temperature range, what is ideal for heat exchange may not be optimal for production such as for growth, egg mass or for feed efficiency. The overall optimum range is mainly dependent on the relative market value of the product produced, in proportion to feed costs. As the ratio of price of feed to gain increases, the best temperature is the one which provides the lowest ratio [22]. Thermo-neutral heat production (HP) at a given intake and ambient temperature determines the range of the comfort zone for an animal. In growing birds, maintenance metabolism is a large part of HP. HP from maintenance will be higher if an animal exerts physical activity in order to gather food and water [23].

Foraging related activities need more energy [24] and increase total heat production. The form of feed which is offered can influence the energy expenditure related to feed consumption activity. The time spent for eating a meal in pelleted form was reduced to one third compared to mash diets. Eating a pellet diet instead of a mash diet saves about $6 \%$ energy [23], which could be beneficial at HT. HP is the result of the heat produced due to energy use associated with digestion processes and the absorption and utilization of nutrients. Together these processes are part of the heat increment caused by feed consumption. Broiler HP is particularly high because of high growth rate, mediated by high feed consumption. The total of heat produced in the course of digestion, excretion and metabolism of nutrients is called heat increment. In the first days of their life poultry need hot climate $\left(32-38^{\circ} \mathrm{C}\right.$ ) (Table 1 ) but the optimal temperature decreases rapidly with age by $2.5-3.0^{\circ} \mathrm{C}$ per week [25]. 


\section{Food Science \& Nutrition Technology}

\begin{tabular}{|c|c|c|}
\hline \multirow{2}{*}{ Class type } & Lower & Upper \\
\cline { 2 - 3 } & \multicolumn{2}{|c|}{ Critical temperature (o) } \\
\hline 1-day-old chicken & 32 & 35 \\
\hline Finishing broiler & 16 & 26 \\
\hline 1-day-old turkey & 35 & 38 \\
\hline Finishing turkey & 16 & 26 \\
\hline Laying hen & 16 & $27-29$ \\
\hline
\end{tabular}

Table1: Lower and upper critical temperature of farm animals at different age or body weight [25].

\section{Effects of Heat Stress on Chickens Production and Products (Egg And Meat)}

Many studies have been published about the effects of heat stress on the efficiency of broiler production. As previously seen, exposure of birds to high environmental temperature generates behavioral, physiological and immunological responses, which impose detrimental consequences to their productivity. Heat stress results in estimated total annual economic loss to the U.S. livestock production industry of $\$ 1.69$ to $\$ 2.36$ billion; from this total, $\$ 128$ to $\$ 165$ million occurs in the poultry industry [26]. In a recent study [27], broilers subjected to chronic heat stress had significantly reduced feed intake $(16.4 \%)$, lower body weight $(32.6 \%)$, and higher feed conversion ratio $(+25.6 \%)$ at 42 days of age.

Many additional studies have shown impaired growth performance in broilers subjected to heat stress [28]. It has been reported that chronic heat exposure negatively affects fat deposition and meat quality in broilers, in a breeddependent manner [8]. Another recent study Zhang Z, et al. [9] demonstrated that chronic heat stress decreased the proportion of breast muscle, while increasing the proportion of thigh muscle in broilers. Moreover, the protein content was lower and fat deposition higher in birds subjected to heat stress. Productivity of laying hens flocks may also be affected by a multitude of factors, including environmental stress (such as heat stress), which is probably one of the most commonly occurring challenges in many production systems around of the world.

Decreased feed intake is very likely the starting point of most detrimental effects of heat stress on production, leading to decreased body weight, feed efficiency, egg production and quality [16]. However, in addition to decreased feed intake, it has been shown that heat stress leads to reduced dietary digestibility, and decreased plasma protein and calcium levels [29]. In a recent study a 12-day heat stress period caused a daily feed intake reduction of $28.58 \mathrm{~g} /$ bird, resulting in a $28.8 \%$ decrease in egg production. Star, et al. [30] reported a reduction of $31.6 \%$ in feed conversion,
$36.4 \%$ in egg production, and $3.41 \%$ in egg weight in laying hens subjected to heat stress. In another study [31], heat stress caused decreased production performance, as well as reduced eggshell thickness, and increased egg breakage. Additionally, heat stress has been shown to cause a significant reduction of egg weight (3.24\%), egg shell thickness (1.2\%), eggshell weight (9.93\%), and eggshell percent $(0.66 \%)$.

The variability of the effects reported may be easily explained by the use of birds of different age or genetic background, as well as due to variable intensity and duration of the heat stress treatments applied. In addition to the decrease in both feed intake and body weight gain, heat stress affects the body composition of broilers causing a lower breast yield, increased abdominal, and intramuscular fat deposition; and this effects of heat stress depends on the poultry breeds. In egg production, heat stress has a significant harmful impact on body weight, and feed consumption of laying hens at peak production, egg weight, shell weight, shell thickness, and gravity. The crucial temperature for poultry is $30^{\circ} \mathrm{C}$, because up to this point birds, through a better feed conversion rate and lower basal metabolic rate, are able to compensate for the energy loss caused by the lower feed intake [22].

Above $30^{\circ} \mathrm{C}$ the feed and energy intake declines to such an extent that birds are no more able to compensate for it, production declines rapidly and the rate of mortality increases. During heat stress birds lose a large amount of carbon dioxide by panting; $\mathrm{CO}_{2}$ however, is essential for Cacarbonate in eggshell formation. Therefore, in addition to an insufficient nutrient supply, the compromised egg shell formation limits the egg production further (egg/day or egg production/number of birds), which can be very substantial as the egg production percentage might decline from $80-90 \%$ to $50-60 \%$, with a $10 \mathrm{~g}$ lower egg weight on average [16]. Generally heat stress affects the poultry production through.

$\checkmark$ decrease feed intake, decrease egg production

$\checkmark$ decrease egg weight

$\checkmark$ decrease shell quality

$\checkmark$ decrease albumen height 


\section{Food Science \& Nutrition Technology}

$\checkmark$ decrease growth

$\checkmark$ decrease hatchability

$\checkmark$ decrease fertility in roosters

$\checkmark$ increase immunosuppressant, increase cannibalism increase mortality

\section{Effect of Heat Stress on Slaughter Processing of Chicken Meat Quality}

Physiological stress can have deleterious effects on the overall performance and body growth of meat-type poultry [16], and this is still a challenging subject for poultry producers and academic. It is estimated that the worldwide demand for poultry products (meat and eggs) will rise exponentially in the coming decades. The human population is expected to increase in $33 \%$ by 2050 and this will result in an increase of overall food production of $70 \%$ and hence, increase the demand of poultry meat to feed this huge human population in next few decades [32].

Broiler production is an important sector of the poultry industry, comprising $25 \%$ of overall meat production, and has increased in 125\% between 1999 and 2009 [33]. Protein from chicken meat is the cheapest meat source for human consumption. However, a wide range of climatic variations greatly influences the productivity of broilers. Stress directly affects the physiology and welfare of poultry, and result in lower profitability [18]. Broilers present optimal feed intake and weight gain when reared within the comfort zone [34]. Poultry growth performance is not only inherited, but it is also greatly affected by the environment [1]. Heat stress has long been recognized as one of the prominent environmental elements influencing meat quality $[35,36]$.

The susceptibility of broilers to heat stress has been increased by continuous selection for fast growth $[37,38]$. Numerous studies have focused on meat quality as affected by heat stress applications just prior to slaughter and found that the occurrence of pale, soft, exudative (PSE) meat has become a growing problem associated with heat stress $[39,40]$. PSE meat is the result of accelerated postmortem glycolysis, which results in a rapid postmortem decline in $\mathrm{pH}$ while carcass temperatures are still high. This combination can result in protein denaturation of the muscle that leads to pale meat color, decreased water holding capacity, and poor texture [40-42]]. It has been reported that acute heat stress can increase lightness and decrease the water holding capacity in the breast muscle of broilers [43-45]. The general approach is to rapidly reduce the carcass temperature after slaughter (within one hr postmortem) by dipping the carcass in ice water. Rapid decline of carcass temperature would reduce the rate of postmortem metabolism, thus slowing the rate of $\mathrm{pH}$ decline [46].

\section{Effects of Heat Stress on Food Safety (Meat and Egg)}

Heat stress during the growth period of broilers has been associated with undesirable meat characteristics and quality loss [47]. Additionally, transportation of broilers from farms to processing facilities under high temperature conditions have also been shown to cause meat quality losses [48]. More recently, food safety has become a major issue to the poultry meat and egg production industry worldwide. In fact, food safety is increasingly being considered an important part of the modern food quality concept. Colonization of birds by foodborne pathogens, such as Salmonella and Campylobacter, and their subsequent dissemination along the human food chain are a major public health and economic concern in poultry meat and egg production.

There is increasing evidence to demonstrate that stress can have a significant deleterious effect on food safety through a variety of potential mechanisms. However, while there is evidence linking stress with pathogen carriage and shedding in farm animals, the mechanisms underlying this effect have not been fully elucidated [49]. Environmental stress has been shown to be a factor that can lead to colonization of farm animals by pathogens, increased fecal shedding and horizontal transmission, and consequently, increased contamination risk of animal products [50]. However, studies have been reported demonstrating that heat stress affects the microbial composition as well as the concentration of shortchain fatty acids in the rumen which is a much more complex microbial system in comparison to the poultry intestinal microbiome. Altered morphology, as well as changes in the microbial community structure in the intestinal tract of broilers subjected to heat stress has been reported [51-65].

\section{Conclusion}

Heat stress is one of the most important environmental stressors challenging poultry production worldwide. The negative effects of heat stress on broilers and laying hens range from reduced growth and egg production to decreased poultry and egg quality and safety. However, a major concern should be the negative impact of heat stress on poultry welfare. As presented in this review, much information has been published on the effects of heat stress on productivity and immune response in poultry (broilers and laying hens). Therefore, data on environmental rearing conditions and their effects on poultry production need to be generated to allow the development of common strategies to face the adverse effects of the climate change. In general, birds react similarly to heat stress, but express individual variation of intensity and duration of responses, which may also be affected by intensity and duration of the heat stress event additionally, increasing evidence indicates that much of the 


\section{Food Science \& Nutrition Technology}

variation in response to heat stress is apparently geneticallybased. Saying this to advice on reducing heat stress in poultry by applying the following situations: Provide cool, clean quality of drinking water, always make sure poultry are in a well-ventilated area in which there is nothing to obstruct the airflow (applied misting/fogging systems can be used), take feed during the coolest part of the day and avoid excessive activity during the hottest period of the day, in peak hours avoid bothering and disturbing the birds.

\section{References}

1. Babinszky L, Halas V, Verstegen MW (2011) Impacts of climate change on animal production and quality of animal food products. In: Blanco J, Kheradmand H (Ed.), Climate change socioeconomic effects. Rijeka: In Tech, pp: 165-190.

2. Selye H (1976) Forty years of stress research: principal remaining problems and misconceptions. Can Med Assoc J 115(1): 53-56.

3. Settar P, Alcin S, Turkmut L, Ozkan S, Cahanar A (1999) Season by genotype interaction related to broiler growth rate and heat tolerance. Poult Sci 78: 1353-1358.

4. Deeb N, Cahaner A (2013) Genotype-by-environment interaction with broiler genotypes differing in growth rate and water consumption of broiler progeny from weight-selected versus non-selected parents under normal and high ambient temperatures. Poult Sci 81: 293-301.

5. Mack LA, Felver-Gant JN, Dennis RL, Cheng HW (2013) Genetic variation alter production and behavioral responses following heat stress in 2 strains of laying hens. Poult Sci 92(2): 285-294.

6. Fedde MR (1998) Relationship of structure and function of the avian respiratory system to disease susceptibility. Poult Sci 77(1): 1130-1138.

7. Marder J, Arad Z (1989) Panting and acid-base regulation in heat stressed birds. Comp Bio chem Physiol A Comp Physiol 94(3): 395-400.

8. Lu Q, Wen J, Zhang H (2007) Effect of chronic heat exposure on fat deposition and meat quality in two genetic types of chicken. Poult Sci 86: 1059-1064.

9. Zhang Z, Jia GQ, Zuo JJ, Zhang Y, Lei J, et al.(2012) Effects of constant and cyclic heat stress on muscle metabolism and meat quality of broiler breast fillet and thigh meat. Poult Sci 91(11): 2931-2937.

10. Dawson WR, Whittow GC (2000) Regulation of Body
Temperature in: Whittow GC (Ed.), Sturk. Avi. Physi, Heat stress and feeding strategies: Syafwan S, World's Poult Sci J 67: 343-390.

11. Etches RJ, John TM, Verrinder GAM (2008) Behavioral and physiological, neuroendocrine and molecular responses to heat stress, Poult Prod in Hot Clim 14: 4980.

12. Rozenboim I, Tako E, Gal-Garber O, Proudman JA, Uni Z (2007) The effect of heat stress on ovarian function of laying hens. Poult Sci 86(8): 1760-1765.

13. Elnagar SA, Scheideler SE, Beck MM (2010) Reproductive hormones, hepatic deiodinase messenger ribonucleic acid, and vasoactive intestinal polypeptideimmunoreactive cells in hypothalamus in the heat stressinduced or chemically induced hypothyroid laying hen. Poult Sci 89: 2001-2009.

14. McDaniel CDm, Hood JE, Parker HM (2004) An attempt at alleviating heat stress infertility in male broiler breeder chickens with dietary ascorbic acid. Int J Poult Sci 3: 593602.

15. Marketon JIW, Glaser R (2008) Stress hormones and immune function. Cel Immunol 252(1-2): 16-26.

16. Mashaly MM, Hendricks GL, Kalamz MA (2004) Effect of Heat Stress on Production Parameters and Immune Responses of Commercial Laying Hens, Poultry Science 83: 889-894.

17. Ghazi SH, Habibian M, Moeini MM, Abdolmohammadi AR (2012) Effects of different levels of organic and inorganic chromium on growth performance and immunocompetence of broilers under heat stress. Biol Trace Elem Res 146: 309-317.

18. Barnett J, Hemsworth P (2003) Science and its application in assessing the welfare of laying hens in the egg industry. Aust Vet J 81(10): 615-624.

19. Bartlett JR, Smith MO (2003) Effects of different levels of zinc on the performance and immunocompetence of broilers under heat stress. Poult Sci 82(10): 1580-1588.

20. Yahav S (2009) Alleviating heat stress in domestic fowl: different strategies. World's Poultry Science Journal 65(4): 719-732.

21. Mount LE (1979) Adaptation to thermal environment: Man and his productive animals. Edward Arnold Limited, Thomson Litho Ltd, East Kilbride, Scotland.

22. Daghir NJ (2008) Nutrient requirements of poultry at high temperature. In: Daghir NJ (Ed.), Poult Prod Hot Cli, 


\section{Food Science \& Nutrition Technology}

pp: 133-160.

23. Gous RM, Morris TR (2005) Nutritional interventions in alleviating the effects of high temperatures in broiler production. World's Poult Sci J 61(3): 463-475.

24. Andersson M, Nordin E, Jensen P (2001) Domestication effects on foraging strategies in fowl. Appli Ani Beh Sci 72: 51-62.

25. FASS (Federation of Animal Science Societies) (2010) Guide for the Care and Use of Agri. Animals in Research and Teaching.

26. St-Pierre NR, Cobanov B, Schnitkey G (2003) Economic losses from heat stress by US livestock industries. J Dairy Sci 86(E Suppl): E52-E77.

27. Sohail MU, Hume ME, Byrd JA, Nisbet DJ, Ijaz A, et al. (2012) Effect of supplementation of prebiotic mannanoligosaccharides and probiotics mixture on growth performance of broilers subjected to chronic heat stress. Poult Sci 91(1): 2235-2240.

28. Attia YA, Hassan RA, Tag El-Din AE, Abou-Shehema BM (2011) Effect of ascorbic acid or increasing metabolizable energy level with or without supplementation of some essential amino acids on productive and physiological traits of slow-growing chicks exposed to chronic heat stress. J Anim Physiol Anim Nutr 95(6): 744-755.

29. Zhou WT, Fijita M, Yamamoto S, Iwasaki K, Ikawa R, et al. (1998) Effects of glucose in drinking water on the changes in whole blood viscosity and plasma osmolality of broiler chickens during high temperature exposure. Poult Sci 77: 644-647.

30. Star L, Juul-Madsen HR, Decuypere E, Nieuwland MG, de Vries Reilingh G, et al. (2009) Effect of early life thermal conditioning and immune challenge on thermotolerance and humoral immune competence in adult laying hens. Poult Sci 88(11): 2253-2261.

31. Lin H, Mertens K, Kemps B, Govaerts T, De Ketelaere B, et al. (2013) New approach of testing the effect of heat stress on eggshell quality: Mechanical and material properties of eggshell and membrane. Br Poult Sci 45: 476-482.

32. UNO-United Nations Organization (2015) Department of Economic and Social Affairs website.

33. Windhorst HW (2011) Global egg production dynamicspast, present and future of a remarkable success story.

34. Al-Aqil A, Zulkifli I, Sazili A, Omar A, Rajion M (2009) The effects of the hot, humid tropical climate and early age feed restriction on stress and fear responses, and performance in broiler chickens. Asi Aus J of Ani Sci 22(11): 1581-1586.

35. Northcutt JK (1994) Influence of Antemortem Treatment on Post Mortem Muscle Properties of Poultry Meat, North Carolina State University.

36. McKee SR, Sams AR (1997) The effect of seasonal heat stress on rigor development and the incidence of pale, exudative turkey meat. Poult Sci 76(11):1616-1620.

37. Altan O, Pabuccuoglu A, Altan A, Konyalioglu S, Bayraktar $H$ (2003) Effect of heat stress on oxidative stress, lipid peroxidation and some stress parameters in broilers. Brit Poult Sci 44: 545-550.

38. Tan GY, Yang L, Q Y Fu, Feng JH, Zhang MH (2010) Effects of different acute high ambient temperatures on function of hepatic mitochondrial respiration, antioxidative enzymes, and oxidative injury in broiler chickens. Poult Sci 89:115-122.

39. Owens CM, McKee SR, Matthews NS, Sams AR (2000) The development of pale, exudative meat in two genetic lines of turkeys subjected to heat stress and its prediction by halothane screening. Poult Sci 79: 430-435.

40. Alvarado CZ, Sams AR (2002) The role of carcass chilling rate in the development of pale, exudative turkey pectoralis. Poult Sci 81: 1365-1370.

41. Woelfel RL, Owens CM, Hirschler EM, MartinezDawson R, Sams AR (2002) The characterization and incidence of pale, soft, and exudative broiler meat in a commercial processing plant. Poult Sci 81(4): 579-584.

42. Wilhelm AE, Maganhini MB (2010) Protease activity and the ultrastructure of broiler chicken PSE (pale, soft, exudative) meat. Food Chem 119(3): 1201-1204.

43. McCurdy RD, Barbut S (1996) Seasonal effect on pale softexudative (PSE) occurrence in young turkey breast meat. Food Res Int 29(3-4): 363-366.

44. Bianchi M, Capozzi F, Cremonini MA, Laghi L, Petracci M, et al. (2004) Influence of the season on the relationships between NMR transverse relaxation data and water holding capacity of turkey breast meat. J Sci Food Agr 84:1535-1540.

45. Aksit M, Yalcin S, Ozkan S, Metin K, Ozdemir D (2006) Effects of temperature during rearing and crating on stress parameters and meat quality of broilers. Poult Sci 85(11):1867-1874.

46. Purslow PP (2005) Intramuscular connective tissue and 


\section{Food Science \& Nutrition Technology}

its role in meat quality. Meat Sci 70(3): 435-447.

47. Sandercock DA, Hunter RR, Nute GR, Mitchell MA, Hocking PM (2001) Acute heat stress-induced alterations in blood acid-base status and skeletal muscle membrane integrity in broiler chickens at two ages: Implications for meat quality. Poult Sci 80(4): 418-425.

48. Dadgar S, Lee ES, Leer TL, Burlinguette N, Classen HL, et al. (2010) Effect of microclimate temperature during transportation of broiler chickens on quality of the pectoralis major muscle. Poult Sci 89: 1033-1041.

49. Rostagno MH (2009) Can stress in farm animals increase food safety risk? Foodborne Pathog Dis 6: 767-776.

50. Verbrugghe E, Boyen F, Gaastra W, Bekhuis L, Leyman B, et al. (2012) The complex interplay between stress and bacterial infections in animals. Vet Microbiol 155: 115127.

51. Belay T, Teeter RG (1996) Broiler water balance and thermo-balance during thermoneutral and high temperature exposure. Poult Sci 72: 116-124.

52. Bonnet S, Geraert PA, Lessire M, Carre B, Guillaumin $S$ (1997) Effect of high ambient temperature on feed digestibility in broilers. Poult Sci 76(6): 857-863.

53. Domingues AR, Pires SM, Halasa T, Hald T (2012) Source attribution of human Salmonellosis using meta-analysis of case-control studies of sporadic infections. Epide Infect 140: 959-969.

54. Geraert PA, Padilha JC, Guillaumin S (1996) Metabolic and endocrine changes induced by chronic heat exposure in broiler chickens: biological and endocrinological variables. Br J Nutr 75: 205-216.

55. Hai L, Rong D, Zhang ZY (2000) The effect of thermal environment on the digestion of broilers. Jour of Ani Physio and Ani Nutr (Berl) 83: 57-64.

56. Imik H, Atasever MA, Urgar S, Ozlu H, Gumus R, et al.
(2012) Meat quality of heat stress exposed broilers and effect of protein and vitamin E. Br Poult Sci 53: 689-698.

57. Kadim I, AL-Qamshui B, Mahgoub O, AL-Marzooqi W, Johnson E (2008) Effect of seasonal temperatures and ascorbic acid supplementation on performance of broiler chickens maintained in closed and open-sided houses. Intern Jou of Poult Sci 7(7): 655-660.

58. Macleod MG, Dabutha LA (1997) Diet selection by Japanese quail (Coturnix coturnix japonica) in relation to ambient temperature and metabolic rate. Briti Poult Sci 38(5): 586-589.

59. Mulder RWAW (1995) Impact of transport and related stresses on the incidence and extent of human pathogens in pig meat and poultry. J Food Safety 15(3): 239-246.

60. Niu ZY, Liu FZ, Yan QL, Li WC (2009) Effects of different levels of vitamin $\mathrm{E}$ on growth performance and immune responses of broilers under heat stress. Poult Sci 88(10): 2101-2107.

61. Puvadolpirod S, Thaxton JP (2000b) Model of physiological stress in chickens 4 Digestion and metabolism. Poult Sci 79(3): 383-390.

62. Sams A (1997) The effect of seasonal heat stress on rigor development and the incidence of pale, exudative turkey meat. Poult Sci 76(11): 1616-1620.

63. Sivakumar A, Singh G, Varshney VP (2010) Antioxidants supplementation on acid base balance during heat stress in goats. Asian-Austral J Ani 23: 1462-1468.

64. Yahav S (2015) Chapter 37-Regulation of Body Temperature: Strategies and Mechanisms A2-Scanes, Colin G. In: Stur Avi Physio $6^{\text {th }}$ (Edn.), San Diego: Academic Press, pp: 869-905.

65. Yahav S, Shinder D, Tanny J, Cohen S (2005) Sensible heat loss: the broilers paradox. Worl Poult Sci Jour 61(3): 419-434. 